\title{
Lethality of suicidal organophosphorus poisoning in an Indian population: exploring preventability Nilamadhab Kar*
}

Address: Wolverhampton City Primary Care Trust, Corner House Resource Centre, 300 Dunstall Road, Wolverhampton, WV6 0NZ, UK

Email: Nilamadhab Kar* - nmadhab@yahoo.com

* Corresponding author

Published: 2I November 2006

Annals of General Psychiatry 2006, 5:17 doi:10.1186/1744-859X-5-17
Received: 05 July 2006

Accepted: 21 November 2006

This article is available from: http://www.annals-general-psychiatry.com/content/5/I/I7

(c) 2006 Kar; licensee BioMed Central Ltd.

This is an Open Access article distributed under the terms of the Creative Commons Attribution License (http://creativecommons.org/licenses/by/2.0), which permits unrestricted use, distribution, and reproduction in any medium, provided the original work is properly cited.

\begin{abstract}
Background: Suicide by organophosphorus poisoning is common in India. Study of factors associated with lethality may suggest methods for prevention.

Methods: Severity of symptoms, biochemical manifestation of poisoning, degree of lethality and the outcome were studied with an aim to explore the modifiable factors associated with lethality and to discuss preventability. Clinical variables were collected; symptoms were rated by the physicians using global impression of severity; and the lethality was assessed by scale for assessment of lethality of suicide attempt (SALSA), in 100 consecutive patients with suicidal organophosphorus poisoning attending a medical college hospital in South India.
\end{abstract}

Results: Fatal outcome $(n=26)$ was significantly associated with higher mean age, lower mean pseudocholinesterase level, longer duration between organophosphorus compound ingestion and specific intervention. All those who died had respiratory failure. Physicians' assessment of symptom severity and lethality as assessed by the SALSA could differentiate those succumbed and survived in a significant proportion.

Conclusion: Majority of cases of organophosphorus poisoning were associated with severe symptoms and higher lethality. Intervention facilities decreasing the period between the ingestion of poison and initiation of treatment might prevent many deaths. Measures like restricting availability and banning more toxic organophosphorus compounds may help.

\section{Background}

Poisoning is a common method of suicide, especially in the developing world [1]. In many Indian reports, the rates of poisoning as suicidal method range from $20.6 \%$ (10.3\% organophosphorus) [2] to $56.3 \%$ (43.8\% organophosphorus) $[3,4]$. It has remained so for almost a century, $44.2 \%$ in $1872-76$ and $49.2 \%$ in 1972 [5]. Reported poisoning rates in the suicide attempters who attend hospital varies from around $40 \%$ to over $80 \%$ [6-8] in many Indian studies. Organophosphorus compounds available as pesticides are amongst the most common poisons used [3,9-12]. In hospital based studies mortality rates associated with pesticides have been reported up to as high as $50-70 \%$ [13]. Considerable proportions of children and adolescent attempters, 50\% males and 60\% females in one study [3], have used this method of attempt. Study of organophosphorus poisoning as a method of suicide attempt, its presentation in hospitals, lethality and outcome following intervention may provide insight for preventing death in a proportion of attempters. 
Specific aim of this study was to evaluate suicide attempt by organophosphorus poisoning in an Indian patient population as they present to a hospital, severity of symptoms as observed by the physicians, biochemical manifestation of poisoning, the lethality of the suicide attempt, and the outcome. It also aimed to discuss the possible preventive ways based on modifiable factors associated with lethality.

\section{Methods}

In a prospective study, consecutive 100 patients with suicidal organophosphorus poisoning attending a medical college hospital in South India were evaluated. Patients with multiple methods of attempt, including multiple substances for poisoning and accidental poisoning were excluded. The informed consent was taken from the relatives and later from the patient if he/she survived the attempt. Age, gender, clinical variables like interval between ingestion of poison and specific intervention (pralidoxime (PAM) injection for this index study), respiratory failure, duration of ventilatory support and mortality were studied. Pseudocholinesterase level was recorded. Manifestations of poisoning were recorded as mild, moderate or severe by the treating physicians as a global impression of severity of the symptoms.

Lethality was considered as the possibility or degree to which any biological change that could have endangered the life of the patient if not rescued or resuscitated. Lethality was studied by global impression of lethality item of the scale for assessment of lethality of suicide attempt (SALSA) with 5-levels of lethality (degree of lethality ranged from subliminal to extremely high) [14]. The mode of attempt, rescuability, degree of help required, maximum severity of physical symptoms manifested and the level of medical intervention required were considered in deciding about the lethality.

The statistical tests were done by SPSS package. The categorical data were analyzed by using chi-square tests and the continuous variables were compared by two-tailed ttests. Statistical significance was defined at the standard 0.05 level.

\section{Results}

There were 68 males and 32 female attempters (male to female ratio 2.1:1). Mean age and standard deviation (SD) of male $(31.5 \pm 12.37$ years) and female $(29.7 \pm$ 15.62 years) attempters were not significantly different $(\mathrm{t}$ : 0.55 , df: $98, \mathrm{p}: 0.58)$. More women $(90.6 \%)$ in contrast to men $(70.6 \%)$ were married $\left(\chi^{2}: 4.93, \mathrm{df}: 1, \mathrm{p}: 0.026\right)$.

Out of the 100 attempters 26 died. Nineteen males $(27.9 \%)$ and 7 females $(21.9 \%)$ succumbed to their attempt (ratio: $2.7: 1$ ); the difference between the propor- tions was not statistically significant. There was no significant difference between the genders regarding the clinical variables studied.

Comparisons of clinical variables of attempters who died with those survived their attempt are given in table 1 . Mean age of the attempters who died was significantly more than that of who survived. Fatal outcome was significantly associated with lower mean pseudocholinesterase level which indicated probability of higher toxicity of ingested substance besides other factors. The duration of organophosphorus compound ingestion and specific intervention was significantly more in those died. The delay was due to many factors including lack of intervention facility locally and the time for travel. All the persons who died had respiratory failure, compared to $51.4 \%$ of the survived.

Severity of symptoms and degree of lethality of considerable proportion of attempts were high. Global impression of severity of symptoms suggested that amongst those who died $42.3 \%$ had moderate and $57.7 \%$ had severe symptoms of poisoning in contrast to $10.8 \%$ mild, $56.8 \%$ moderate and $32.4 \%$ severe symptoms of those who survived ( $\chi^{2}: 6.7$, df: $\left.2, \mathrm{p}<0.05\right)$. Even though $61.5 \%$ with severe symptoms did survive, impression of the physicians regarding severity of symptoms significantly differentiated the outcome. Evaluation of lethality through SALSA suggested a trend with higher lethality indicator being associated with higher proportion of death in the attempters; for example, $75 \%$ of the attempters with extremely high lethality died compared to $38.1 \%$ with high and $21.4 \%$ of the moderate lethality $\left(\chi^{2}: 34.2\right.$, df: 1 , $\mathrm{p}<0.000)$.

\section{Discussion}

The study tried to evaluate lethality in organophosphorus poisoning and to explore preventability. As reported in many previous studies males were more represented in the suicidal patients seen in a hospital setting [15]. A larger proportion of them compared to females died, but the difference was statistically not significant. Male/ female ratio in the committers (2.7.1) is wider than the overall national ratio of $1.4: 1$ in suicide [1]; suggesting that in organophosphorus poisoning there is considerable preponderance of males in hospital setting. It might be relatively easier for men, some as farmers, to avail pesticides to use as suicide method as observed in other studies [3]. Concerns regarding increased suicide by farmers in India are well known $[16,17]$.

Alarmingly $22 \%$ of attempters were 20 years old or less ( $17 \%$ within the age of 18 to 20 years); however all of them survived. It supports the reports that adolescents are a major risk group for suicide attempt [18]. Proportions of 
Table I: Clinical variables associated with mortality following suicidal organophosphorus poisoning

\begin{tabular}{|c|c|c|c|c|c|}
\hline \multirow[t]{2}{*}{ Variables } & \multirow[t]{2}{*}{$\mathrm{n}$} & \multicolumn{2}{|c|}{ Succumbed $(n=26)$} & \multicolumn{2}{|c|}{ Survived $(n=74)$} \\
\hline & & $\mathrm{n}$ & $\%$ & $\mathrm{n}$ & $\%$ \\
\hline \multicolumn{6}{|l|}{ Gender } \\
\hline Male & 68 & 19 & 27.9 & 49 & 72.1 \\
\hline Female & 32 & 7 & 21.9 & 25 & 78.1 \\
\hline \multicolumn{6}{|l|}{ Age group in years } \\
\hline$<18$ & 5 & 0 & 0.0 & 5 & 100.0 \\
\hline $18-20$ & 17 & 0 & 0.0 & 17 & 100.0 \\
\hline $21-30$ & 42 & 12 & 28.6 & 30 & 71.4 \\
\hline $31-40$ & 20 & 8 & 40.0 & 12 & 60.0 \\
\hline $4 I-50$ & 6 & 2 & 33.3 & 4 & 66.7 \\
\hline $51+$ & 10 & 4 & 40.0 & 6 & 60.0 \\
\hline Mean Age (SD) a & & 35.88 & $(13.17)$ & 29.02 & $(13.2)$ \\
\hline Mean pseudocholinesterase level (SD) b & & 1448.9 & (I I 20.9) & 3165.5 & $(2715.2)$ \\
\hline Respiratory failure ${ }^{c}$ & 64 & 26 & 40.6 & 38 & 59.4 \\
\hline Mean ventilatory duration in hours (SD) & & 7.15 & $(6.01)$ & 5.17 & $(7.46)$ \\
\hline \multicolumn{6}{|l|}{ Symptoms of poisoning $d$} \\
\hline Mild & 8 & 0 & 0.0 & 8 & 100.0 \\
\hline Moderate & 53 & 11 & 20.8 & 42 & 79.2 \\
\hline Severe & 39 & 15 & 38.5 & 24 & 61.5 \\
\hline \multicolumn{6}{|l|}{ Lethality e } \\
\hline Subliminal & 20 & 0 & 0.0 & 20 & 100.0 \\
\hline Low & 15 & 0 & 0.0 & 15 & 100.0 \\
\hline Moderate & 28 & 6 & 21.4 & 22 & 78.6 \\
\hline High & 21 & 8 & 38.1 & 13 & 61.9 \\
\hline Extremely high & 16 & 12 & 75.0 & 4 & 25.0 \\
\hline Mean PAM interval in hours (SD) $f$ & & 7.24 & $(6.28)$ & 4.37 & $(4.63)$ \\
\hline
\end{tabular}

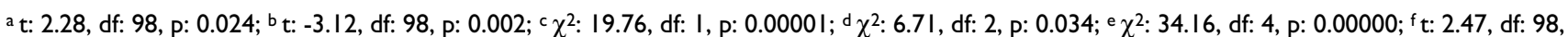
$\mathrm{p}: 0.015$; Percentages are from the number of patients in that category of variable; figures in parentheses are SD.

attempters who died were more in age groups of 31-40 years and 51 years and above, suggesting probability of higher risk of suicidal death in these age ranges. Mean age of those who died was significantly more than that of survivors.

Mean pseudocholinesterase level was significantly less in those who died compared to survivors. Though there are controversies about the correlation between plasma cholinesterase activity and the severity of organophosphorus poisoning [19], it is a marker of the organophosphorus intoxication. Number of hours passed between ingestion of poison and initiation of specific treatment had significantly influence on the outcome. It was significantly more in those who died. Respiratory failure which was observed in all who died and in $51.4 \%$ of survivors indicated the severity of the attempts and was one of the significant indicators for outcome.

Lethality is an important clinical variable for both medical and psychiatric evaluation and management. In contrast to intent-to-die which is a subjective measure, lethality is objective, more descriptive of the behaviour, and often correlate with the degree of intent [20]. In the index study findings indicated that organophosphorus poisoning in most attempters was clinically severe with higher degree of lethality. Physicians' assessment of symptom severity and lethality as assessed by the SALSA were able to categorize attempts into different grades of severity and lethality which could differentiate the outcome in a significant proportion.

It is presumable that severity of symptoms and toxicity of the compounds are related. In the index study most patients had moderate to severe symptoms, moderate to extremely high lethality and respiratory failure, besides significantly lower pseudocholinesterase level in those succumbed to the poisoning. Though toxicity of ingested substances was not directly studied; and many factors contribute to severity of poisoning, the above observations indirectly suggest probability of higher toxicity of ingested substances in most cases. Banning of extremely toxic pesticides and restriction of their use have been urged by World Health Organisation [13]. Restriction of availability of suicide methods has received some attention as a possible way of suicide prevention $[4,21,22]$, though it is also reported that when one method is restricted then the suicidal methods change [4]. Legislation on drug availa- 
bility and packaging has been effective elsewhere [13,22]. In addition, involving another individual from farmer community in the sale, use and safe disposal of the remaining content of organophosphorus compounds may help. Public education in this regard may be needed.

Efforts to minimize the period between ingestion of poison and initiation of specific treatment may help to decrease the chance of death in some. Most part of the duration from ingestion of poisoning to initiation of treatment was spent travelling/arranging transport to the hospital. In the developing world many attempters are referred to secondary and tertiary centres for lack of facility locally. It is a common observation that many attempters are brought dead to hospital [8]. Delay in arriving in hospital with facilities seriously curtails their effectiveness. Availability of basic facilities for treatment of organophosphorus poisoning at primary health centres (PHC) and local hospitals may change this negative outcome for many, if not for all. Increasing the ability of the primary care facilities to manage the medical complication of suicide attempt is a recognized intervention in China [21]. Periodic training to the doctors and other health care staff in community, improving their skills in assessment and management may help in dealing with more cases in community effectively in time before the duration of ingestion and specific intervention gets prolonged. It may help to have clear protocol and guidelines available for managing poisoning cases. The facilities for initiating treatment sooner and respiratory support locally and while transferring the patient (if needed) may increase the chance of survival for many attempters. However these suggestions would require further focused study for their effectiveness.

There are few limitations of the study. The sample was taken from a tertiary level of health care system. The findings in community sample attending primary or secondary centres may be different. Variables which may be clinically relevant regarding outcome such as existing other morbidities and treatments were not studied.

\section{Conclusion}

In the index study a typical attempter who died was around 35 years of age, male, with low pseudocholinesterase level, respiratory failure, moderate to severe symptoms, moderate to extremely high lethality and an average duration of around seven hours from ingestion to specific intervention. Assessments of severity and lethality of the attempts were able to differentiate the attempters from the committers in most cases. Suicide prevention is a much broader multi-agency issue; and emphasis is given to preventing the act of attempt itself. However efforts to decrease the period between the ingestion and initiation of treatment, restricting availability of organophosphorus compounds, and banning more toxic ones may prevent some suicidal deaths following organophosphorus poisoning. Organophosphorus poisoning being a very common method of suicide attempt in developing world deserves specific attention.

\section{Competing interests}

The author(s) declares that they have no competing interests.

\section{Authors' contributions}

NK conceptualized, analyzed and interpreted data, and wrote the paper.

\section{Acknowledgements}

Quality of Life Research and Development Foundation supported the study in part. Purusottam Mishra, MD, Associate Professor of Medicine, Kasturba Medical College, Manipal, India helped in data collection.

\section{References}

I. Vijayakumar L: Suicide prevention: the urgent need in developing countries. World Psychiatry 2004, 3(3): I58-159.

2. Ponnudurai R, Heyakar J: Suicide in Madras. Indian Journal of Psychiatry 1980, 22:203-205.

3. Gururaj G, Isaac MK: Epidemiology of suicide in Bangalore. NIMHANS Publication No. 43, Bangalore; 2001.

4. Nandi DN, Mukherjee SP, Banerjee G, Ghosh A, Boral GC, Chowdhury $\mathrm{A}, \mathrm{Bose} \mathrm{J}$ : Is suicide preventable by restricting the availability of lethal agents? A rural survey of West Bengal. Indian Journal of Psychiatry 1979, 21:25 I-255.

5. Nandi DN, Banerjee G, Boral GC: Suicide in West Bengal - A century apart. Indian Journal of Psychiatry 1978, 20:155-160.

6. Badrinarayana A: Suicide attempt in Gulbarga. Indian Journal of Psychiatry 1977, 19(4):69-70.

7. Kar N: Psychosocial aspects of suicide attempt. MD Thesis, Utkal University, Bhubaneswar 1996.

8. Arun M: A comparative analysis of suicide and parasuicide. MD thesis, MAHE, Manipal 2002.

9. Chugh SN, Aggarwal N, Dabla S, Chhabra B: Comparative evaluation of "Atropine Alone" and "Atropine with Pralidoxime (PAM)" in the management of organophosphorus poisoning. Journal of Indian Academy of Clinical Medicine 2005, 6(I):33-37.

10. Rao CHS, Venkateswarlu V, Surender T, Eddleston M, Buckley NA: Pesticide poisoning in south India: opportunities for prevention and improved medical management. Tropical Medicine and International Health 2005, 10(6):58I-588.

1 I. Eddleston M, Szinicz L, Eyer P, Buckley N: Oximes in acute organophosphorus pesticide poisoning: a systematic review of clinical trials. J Med 2002, 95:275-283.

12. Latha KS, Bhat SM: Suicide attempts among youth: Correlates of medical lethality. Behavioural Medicine Journal I999, 2(I):2I-29.

13. Wadia RS: Treatment of organophosphate poisoning. Indian J Crit Care Med 2003, 7:85-87.

14. Kar N: Scale for Assessment of Lethality of Suicide Attempt Quality of Life Research and Development Foundation, Bhubaneswar; 2002.

15. Arun M, Yoganarasimha K, Palimar V, Kar N, Mohanty M: Parasuicide - an approach to the profile of victims. Journal of Indian Academy of Forensic Medicine 2004, 26(2):58-61.

16. Venugopal $D$, Jagadisha : An Indian perspective of farmer stress - a priority area for future research. International Journal of Social Psychiatry 2000, 46(3):23I-235.

17. Sunder M: Suicide in farmers in India. British Journal of Psychiatry 1999, 175:585-586.

18. Kar N, Pany M, Mishra BN, Sengupta J, Das I: Risk factors of adolescent suicide attempt. Journal of Eastern Zonal Branch of Indian Psychiatric Society 1996, I(I): 17-22.

19. Nouira S, Abroug F, Elatrous S, Boujdaria R, Bouchoucha S: Prognostic value of serum cholinesterase in organophosphate poisoning. Chest 1994, 106(6): 1811-1814.

20. Hamdi E, Amin $Y$, Matter T: Clinical correlates of intent in attempted suicide. Acta Psychiatr Scand I99I, 83:406-4I I. 
21. Phillips M: Suicide prevention in developing countries: where should we start? World Psychiatry 2004, 3(3): I56-157.

22. Gunnell D, Frankel S: Prevention of suicide: Aspirations and evidence. BMJ I994, 308: I227- 233.

Publish with Bio Med Central and every scientist can read your work free of charge

"BioMed Central will be the most significant development for disseminating the results of biomedical research in our lifetime. " Sir Paul Nurse, Cancer Research UK

Your research papers will be:

- available free of charge to the entire biomedical community

- peer reviewed and published immediately upon acceptance

- cited in PubMed and archived on PubMed Central

- yours - you keep the copyright

Submit your manuscript here:

http://www.biomedcentral.com/info/publishing_adv.asp 